\section{Psychotherapy and Psychosomatics}

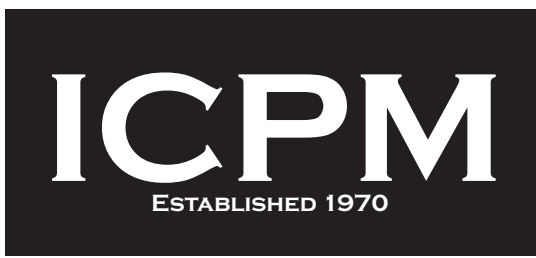

Psychother Psychosom 2010;79:199 DOI: 10.1159/000304471

Published online: April 7, 2010

\title{
28th European Conference on Psychosomatic Research (ECPR)
}

The '28th European Conference on Psychosomatic Research' will take place in Innsbruck on July 2-3, 2010. The theme of the conference will be 'Psychosomatic Medicine in Different Medical Settings - From Basic Care to Specialization'. The congress follows the 'Annual Meeting of the European Society of Consultation-Liaison Psychiatry and Psychosomatics' with the same conference goals: bio-psycho-social aspects of medical care in different settings from primary care to specialization. Worldwide high-technically oriented medicine is expanding to its financial and ethical limits. As a counterpart, psychosocial and psychosomatic care is a necessary way to foster the health of doctors, therapists and patients. The topics of the congress cover the following areas: psychosomatic aspects in primary care, cardiology, oncology, gastroenterology, gynecology, fertility medicine, dermatology, neurobiology, genetics, quality assurance and psychotherapy. Symposia, plenary lectures, clinical courses and poster sessions will open a forum for discussion of research and clinical reality.

Members of the International College of Psychosomatic Medicine will have a reduced registration fee.

We invite all to join in fruitful dialogue in Innsbruck.

Gerhard Schüssler, Congress President Stefan Höfer, Congress Secretary 